This item was submitted to Loughborough's Research Repository by the author.

Items in Figshare are protected by copyright, with all rights reserved, unless otherwise indicated.

\title{
Short-term outcome of treatment limitation discussions for newborn infants, a multicentre prospective observational cohort study
}

\section{PLEASE CITE THE PUBLISHED VERSION}

http://dx.doi.org/10.1136/archdischild-2016-310723

\section{PUBLISHER}

(C) The authors. Published by the BMJ Publishing Group

\section{VERSION}

AM (Accepted Manuscript)

\section{PUBLISHER STATEMENT}

This work is made available according to the conditions of the Creative Commons Attribution-NonCommercialNoDerivatives 4.0 International (CC BY-NC-ND 4.0) licence. Full details of this licence are available at: https://creativecommons.org/licenses/by-nc-nd/4.0/

\section{LICENCE}

CC BY-NC-ND 4.0

\section{REPOSITORY RECORD}

Aladangady, Narendra, Chloe Shaw, Katie Gallagher, Elizabeth Stokoe, and Neil Marlow. 2019. "Short-term Outcome of Treatment Limitation Discussions for Newborn Infants, a Multicentre Prospective Observational Cohort Study". figshare. https://hdl.handle.net/2134/23437. 


\section{Title: Short-term outcome of treatment limitation discussions for newborn infants, a multi-centre prospective observational cohort study}

Narendra Aladangady, Consultant Neonatologist and Hon Clinical Professor in Child Health, Homerton University Hospital NHS Foundation Trust, Homerton Row, London and Barts and the London School of Medicine and Dentistry, Queen Mary University of London

Chloe Shaw, Research Associate, Academic Neonatology, UCL Institute for Women's Health, London

Katie Gallagher, Honorary Senior Research Associate, Academic Neonatology, UCL Institute for Women's Health, London

Elizabeth Stokoe, Professor of Social Interaction, Department of Social Sciences, Loughborough University, Loughborough

Neil Marlow, Professor of Neonatal Medicine, Academic Neonatology, UCL Institute for Women's Health, London

For Collaborators Group.

PUBLISHED in ARCHIVES OF DISEASE IN CHILDHOOD: F\&E EDITION, online Nov 2016

Aladangady N, et al. Arch Dis Child Fetal Neonatal Ed 2016;0:F1-F6. doi:10.1136/archdischild-2016-310723

Corresponding author:

Prof Narendra Aladangady

Consultant Neonatologist

Homerton University Hospital

Homerton Row

London E9 6SR

United Kingdom

Email: narendra.aladangady@homerton.nhs.uk

Tel: +44 (0) 2085105555

Fax: $+44(0) 20$ 
SUMMARY POINTS BOX:

What is already known on this topic?

- Around $60 \%$ of neonatal deaths occur following limitation of life sustaining treatment in the UK

- Previous research is based on retrospective medical notes review of babies who died in neonatal units or single tertiary centre prospective studies

- Some babies survive after discussions about life sustaining treatment limitation

What this study adds:

- Population based prospective multicentre data describing the short term outcomes of limiting life sustaining treatment conversations between the neonatal clinical team and parents

- A significant proportion of parents do not agree with the clinical team to limit life sustaining treatment to their babies

- A proportion of babies do survive following parents decision to continue life sustaining treatment

- Infrequently babies do survive after a joint decision to limit life sustaining treatment 


\section{Title: Short-term outcome of treatment limitation discussions for newborn infants, a multi-centre prospective observational cohort study}

Objective: To determine the short-term outcomes of babies for whom clinicians or parents discussed the limitation of life sustaining treatment (LST).

Design: Prospective multicentre observational study.

Setting: Two Level 3, six Level 2 and one Level 1 neonatal unit in the North-East London Neonatal Network.

Participants: A total of 87 babies including 68 for whom limiting LST was discussed with parents and 19 babies died without discussion of limiting LST in the labour ward or neonatal unit.

Outcome measures: Final decision reached after discussions about limiting LST and neonatal unit outcomes (death or survived to discharge) for babies.

Results: Withdrawing LST, withholding LST and DNR order was discussed with 48,16 and 4 parents respectively. In 49/68 (72\%) cases decisions occurred in Level 3 and 19 cases in Level 2 units. Following the initial discussions, $34 / 68$ parents made the decision to continue LST. In $33 / 68$ cases, a second opinion was obtained. The parents of $14 / 48$ and $2 / 16$ babies did not agree to withdraw and withhold LST respectively. Forty-seven out of 87 babies (54\%) died following limitation of LST, 28/87 (32\%) died receiving full intensive care support, 5/87 (6\%) survived following a decision to limit LST and 7/87 (8\%) babies survived following decision to continue LST.

Conclusion: A significant proportion of parents chose to continue treatment following discussions regarding limiting LST for their babies, and a proportion of these babies survived to 
neonatal unit discharge. The long-term outcomes of babies who survive following limiting LST discussion need to be investigated. 


\section{Introduction:}

Survival of extreme preterm and sick term newborn babies has improved in the last two decades due to advances in antenatal, perinatal and neonatal care ${ }^{12}$. However, for some babies the provision of full intensive care, including mechanical support for ventilation, may not be considered to be in their best interest as survival may result in considerable adverse neurodevelopmental outcomes impacting upon the infants' family, health care services and society ${ }^{3-5}$. The provision of Life Sustaining Treatment (LST) in such circumstances has been questioned by professionals ${ }^{67}$ and parents ${ }^{8}$. Guidelines on clinical, ethical and legal aspects of limiting LST for newborn babies have been produced by regulatory ${ }^{9}$, professional $^{10}$ and independent ${ }^{11}$ bodies in the UK. Similar guidelines are available in the USA ${ }^{12}$ and other European countries ${ }^{13}$.

The proportion of deaths that follow limitation of LST in neonatal units appears to be increasing ${ }^{21415}$. Despite an increase in this practice, there have been no population based prospective multicentre studies of families in whom decisions about the limitation of LST for their baby have been discussed ${ }^{11} 16$. In this study we have determined the immediate outcomes of babies for whom clinicians or parents have started considering the withholding or withdrawal of LST and/or institution of "do not resuscitate" (DNR) orders, to determine the prevalence of such conversations and the agreement of the parents to consider redirection of care. 


\section{Method:}

Nine neonatal services [two with neonatal intensive care units (Level 3), six local neonatal units (Level 2) and one special care baby unit (Level 1)] in the North East London Neonatal Network participated. Babies were eligible for the study if the limitation of LST was discussed by the attending neonatologists with parents or among professionals, or if a live born baby died in the labour ward or neonatal unit, over a 12 month period from 6 June 2013 to 5 June 2014. Among babies meeting these criteria there were no exclusions. Limiting LST decision was categorised as withdrawal (withdrawal of treatment that has already started), withholding (withholding of treatment that has not been started) and Do Not Resuscitate (DNR) $\operatorname{Order}^{10}{ }^{17}$ based on the highest modality of treatment limitation discussed (e.g. baby was categorised under withdrawal of care group where both options of withholding and withdrawal of care was discussed, and categorised under withholding of care where both withholding and DNR discussed). Babies that died without prior discussion of limiting care were considered as having received appropriate full LST. Eligible babies were prospectively identified by local investigators (a consultant neonatologist or paediatrician and research nurse) through daily discussions with the attending consultants. Local investigators were regularly reminded about study eligibility criteria by telephone or email (fortnightly for the first three months and subsequently once a month) by the researchers (NA \& CS).

A local investigator recorded anonymised data using a secure on-line 'Research Electronic Data Capture' (REDCap) ${ }^{18}$ database, which captured details of clinical factors, demographics, outcomes of limiting LST conversations, reasons for limiting LST, the circumstance of limiting 
LST considered as per RCPCH guidelines ${ }^{10}$ and neonatal unit outcomes for babies (death or survived to discharge). Limiting LST was discussed with parents after reaching a consensus agreement among clinical team including nursing staff ${ }^{1017}$. Where limiting LST was considered (antenatal ward, delivery suite and neonatal unit) we collected details of treatment subsequent to the first conversation. Pregnant mothers whose fetus had a major congenital anomaly or who had threatened preterm labour at $\geq 23$ weeks of gestation were routinely counselled by a senior neonatal doctor. Before 23 weeks of gestation, parents were counselled on request of neonatologist opinion or where they insisted that the obstetric team actively resuscitate their baby. Data were collected by reviewing medical records and validated by the local principal investigator at each participating hospital. A unique patient identification number was generated for each baby using their NHS number to avoid duplicate entry and to track babies on transfer between hospitals. This also helped to support the gathering of data for the entire neonatal journey until hospital discharge or death.

Statistical analysis: continuous variables were compared by Mann-Whitney U Test; $p$ value of $<0.05$ was considered significant. Data were analysed using SPSS 22.0 software.

The study was approved by the East London Research Ethics Committee (REC no: 12/LO/1949), and by the Research and Development (R\&D) Department of participating hospitals. Parent consent was not required as we used anonymised routinely collected data from medical records. 


\section{Results:}

We identified 87 babies who had died or for whom limiting LST was considered. The distribution of gestational age was bimodal, with $<27$ weeks $(n=42)$ and $>36$ weeks $(n=25)$ being most frequent and 27-36 weeks $(n=20)$ being least frequent (Figure 1). Fifty-eight babies were male and 17 babies were from twin pregnancies. Maternal ethnic background was Caucasian $(n=30)$, Asian $(n=28)$, Black $(n=22)$, mixed/other $(n=5)$ and not recorded for 2 babies. The median maternal age was 32 (range 16 to 47) years; 67 mothers were married or co-habiting and nine were single (no information recorded for 11 cases).

In this population (Figure 2), 19 babies died without joint consideration of limitation of treatment (Table 1), and the option of limiting LST was explored with parents of 68 babies. In two cases discussions about the option of limiting LST were held among the clinical team but not with parents as clinical team were unable to reach a consensus decision. Limitation of LST was first raised by clinicians in 65 cases $(96 \%)$ and by parents in three [one baby with severe HIE (41 weeks, discharged home on day 55), and two extremely preterm babies (one 23 weeks with respiratory failure and one 25 weeks with bilateral haemorrhagic parenchymal infarcts, both of whom died on day three)]. Conversations occurred during the antenatal period with parents of 14 babies and in the delivery room in 11 . Fifty one conversations (73\%) took place in a Level 3 and 19 in Level 2 neonatal units. In 66 of 68 cases, the conversation was led by a Consultant Neonatologist (two antenatal discussions with women threatening delivery at 21 and 23 weeks of gestation were led by a Registrar). Additionally, at least one junior doctor, nurse and/or sister 
in-charge was involved in all cases. The baby's mother was involved in 65 conversations along with the father in 53 (Table 2).

Table 1: Babies who died receiving full care without any discussion to limit LST ( $n=19)$

\begin{tabular}{|c|c|c|c|}
\hline Age at death (days) & $\begin{array}{l}\text { Gestational age } \\
\text { at birth (weeks) }\end{array}$ & Place of death & Main cause of death \\
\hline \multirow[t]{3}{*}{$<0.5$} & 21 to $22(n=4)$ & LW & Extreme prematurity \\
\hline & $26(n=2)$ & $\begin{array}{l}\operatorname{LW}(n=1) \\
\operatorname{NICU}(n=1)\end{array}$ & $\begin{array}{l}\text { 1.PROM with pulmonary hypoplasia } \\
\text { 2.Bilateral Pneumothorax }\end{array}$ \\
\hline & $41(n=1)$ & LW & Congenital pneumonia \\
\hline \multirow[t]{3}{*}{1 to 5} & $24(=1)$ & $\mathrm{NICU}$ & Tension pneumothorax \\
\hline & $25(n=2)$ & NICU & $\begin{array}{l}\text { 1.Pulmonary haemorrhage } \\
\text { 2.Pneumonia }\end{array}$ \\
\hline & $30(n=1)$ & $\mathrm{NICU}$ & Cardiomyopathy \\
\hline \multirow[t]{5}{*}{7 to 47} & $24(n=3)$ & $\mathrm{NICU}$ & $\begin{array}{l}\text { 1.Pseudomonas infection with } \\
\text { pulmonary haemorrhage } \\
\text { 2.IVH with hydrocephalus and } \\
\text { cardiac arrest } \\
\text { 3.NEC - died in theatre }\end{array}$ \\
\hline & $25(n=2)$ & $\mathrm{NICU}$ & $\begin{array}{l}\text { 1.Large IVH with hydrocephalus } \\
\text { 2.NEC - post-operative death }\end{array}$ \\
\hline & $26(n=1)$ & $\mathrm{NICU}$ & $\begin{array}{l}\text { Bronchopulmonary dysplasia and } \\
\text { sepsis }\end{array}$ \\
\hline & $27(n=1)$ & $\mathrm{NICU}$ & $\begin{array}{l}\text { Bronchopulmonary dysplasia and } \\
\text { cardiac arrest }\end{array}$ \\
\hline & $39(n=1)$ & $\mathrm{NICU}$ & Congenital Diaphragmatic Hernia \\
\hline
\end{tabular}

LW - Labour Ward, NICU - Neonatal Intensive Care Unit, IVH - Intra-ventricular Haemorrhage 
Table 2: Clinical team, family and other members involved in limiting LST discussion $(n=68)$

\begin{tabular}{|l|c|}
\hline Clinical team members involved & Number of cases \\
\hline Neonatal Consultant & 66 \\
\hline Neonatal Registrars & 60 \\
\hline Advanced Neonatal Nurse Practioners (ANNP) & 11 \\
\hline Junior doctors (ST1-3) & 35 \\
\hline Nurses (B5/6/7) & 42 \\
\hline Sister/Charge Nurse & 46 \\
\hline Other professionals (e.g. Therapist) & 9 \\
\hline Family and other members involved & Number of cases \\
\hline Mother & $65^{*}$ \\
\hline Father & $53^{* *}$ \\
\hline Grand parents & 9 \\
\hline Older sibling & 1 \\
\hline Extended family members & 15 \\
\hline Friends & 2 \\
\hline Religious representative & 5 \\
\hline Hospital Counsellor & 10 \\
\hline Other & 8 \\
\hline
\end{tabular}

*Three cases where mother was not involved: one mother died in labour ward, one family preferred mother not to be involved (cultural preference) and one mother had severe learning difficulty. Father was involved in discussions to limit LST in all three cases.

**Cases where father was not involved $(n=15)$ : mother $(n=14)$, grandparents $(n=5)$ or extended family members $(n=5)$ were involved.

The underlying conditions prompting consideration of limitation of LSTs were extreme prematurity, congenital anomaly and severe asphyxial encephalopathy (table 3). Limiting LST was considered in situations where imminent $(n=16)$ or inevitable death $(n=27)$ was expected or where limited quality of life was anticipated because of the burden of illness and/or underlying condition $(n=3)$, or lack of ability to derive benefit from further treatment $(n=22)$. Forty-eight discussions concerned withdrawing LST, 16 withholding LST and 4 the establishment of a DNR order. 
Table 3: Reasons for considering limiting LST $(n=68)$

\begin{tabular}{|l|c|}
\hline Reasons for limiting LST consideration & $\begin{array}{c}\text { Number } \\
\text { of cases }\end{array}$ \\
\hline 1.Extremely preterm babies & 2 \\
\hline 1.1 Severe Intra-ventricular Haemorrhage (IVH) & 6 \\
\hline 1.2 IVH with Bilateral Haemorrhagic Parenchymal Infarction (HPI) & 2 \\
\hline 1.3 IVH with Unilateral Haemorrhagic Parenchymal Infarction (HPI) & 3 \\
\hline 1.4 Multi-organ failure & 17 \\
\hline 1.5 Other (e.g. respiratory failure, sepsis, NEC) & 21 \\
\hline 2.Major congenital/chromosomal abnormality & 17 \\
\hline 3.Severe Hypoxic Ischaemic Encephalopathy (HPE) &
\end{tabular}

Following the initial discussions with the clinical team, 34 (50\%) parents made the decision to continue offering LST to their babies. In one case the parents could not agree a course. The recorded bases for these decisions were non-acceptance of diagnosis or prognosis $(n=12)$, religious ( $n=10)$, cultural $(n=3)$, personal $(n=13)$ or uncertain $(n=11)$. In $33(49 \%)$ cases, a second opinion was sought from another neonatal consultant, either from the same unit $(n=20)$ or another hospital ( $n=10)$. Other sub-specialists (Cardiologist, Neurologist) were involved in 6 cases, and Fetal Medicine Specialists from another hospital were involved in 4 cases. The median number of conversations held between professionals and parents to reach final decision was 3 (range: 1 to 12) and time between initial discussion and final decision was 1 (on the same day) to 139 ) days. At the end of this process, the parents of $14 / 48$ (29\%) babies discussed the option to withdraw LST, and parents of $2 / 16(13 \%)$ babies discussed the option to withhold LST, decided to continue LST. In contrast, 4 cases in which the highest modality of treatment limitation discussed was non-resuscitation (DNR), and in all cases parents chose this option (Figure 2). There was no association between maternal ethnicity, religion, having 
previous children and final decision to limit LST or not. Legal advice was not requested in any of the cases.

Of the 87 babies included, 47 (54\%) died following limitation of LST, 28 (32\%) died receiving full intensive care support, 5 (6\%) survived following a decision to limit LST and 7 (8\%) babies survived following decision to continue LST. The birth weight ( $p$ 0.006) and gestational age at birth ( $p$ 0.018) of babies who survived following decision to continue LST were higher compared to babies who died following decision to limit LST (Table 4). Further clinical and neonatal unit outcome details of babies survived $(n=12)$ are presented in table 5 . The mean age at death was 10.78 (SD 26.1) days for babies whose LST was limited and 20.63 (SD 38.2) days for those who continued to receive full LST ( $p$ 0.189).

Table 4: Outcomes and demographic characteristics of babies studied $(n=87)$

\begin{tabular}{|l|c|c|c|c|}
\hline Characteristics & $\begin{array}{c}\text { Baby died } \\
\text { following } \\
\text { limiting LST } \\
(\mathrm{n}=47)\end{array}$ & $\begin{array}{c}\text { Baby survived } \\
\text { following } \\
\text { decision to limit } \\
\text { LST } \\
(\mathrm{n}=5)\end{array}$ & $\begin{array}{c}\text { Baby died } \\
\text { receiving } \\
\text { full LST } \\
(\mathrm{n}=28)\end{array}$ & $\begin{array}{c}\text { Baby survived } \\
\text { following } \\
\text { decision to } \\
\text { continue LST } \\
(\mathrm{n}=7)\end{array}$ \\
\hline Birth Weight (g)* & $\begin{array}{c}1424 \\
(365-4420)\end{array}$ & $\begin{array}{c}620 \\
(520-3880)\end{array}$ & $\begin{array}{c}760 \\
(325-4540)\end{array}$ & $\begin{array}{c}2980 \\
(865-4170)\end{array}$ \\
\hline $\begin{array}{l}\text { Gestational age at birth } \\
\text { (weeks)* }\end{array}$ & 30 & 24 & 26 & 37 \\
\hline Male:Female & $33: 14$ & $(23-40)$ & $(21-41)$ & $(26-41)$ \\
\hline
\end{tabular}

*Results are in median (range) 
Table 5: Clinical details and short-term outcomes of babies survived following limiting Life Sustaining Treatment (LST) discussion ( $n=12$ )

\begin{tabular}{|c|c|c|c|c|c|c|c|}
\hline $\begin{array}{l}\text { Baby } \\
\text { number }\end{array}$ & $\begin{array}{c}\text { Birth } \\
\text { weight } \\
\text { (grams) }\end{array}$ & $\begin{array}{l}\text { Gestation } \\
\text { at birth } \\
\text { (weeks) }\end{array}$ & Gender & $\begin{array}{l}\text { Limiting LST } \\
\text { Discussion }\end{array}$ & $\begin{array}{l}\text { Final decision } \\
\text { outcome }\end{array}$ & Diagnosis & $\begin{array}{l}\text { Neonatal unit } \\
\text { outcome }\end{array}$ \\
\hline 1 & 3020 & 37 & Female & WH - NICU & $\begin{array}{l}\text { Treatment } \\
\text { limited }\end{array}$ & Severe HIE & $\begin{array}{l}\text { Discharge to } \\
\text { hospice }\end{array}$ \\
\hline 2 & 3880 & 40 & Male & DNR - NICU & $\begin{array}{c}\text { Treatment } \\
\text { limited }\end{array}$ & Severe HIE & Discharged home \\
\hline 3 & 2980 & 41 & Male & WD - NICU & $\begin{array}{l}\text { Treatment } \\
\text { continued }\end{array}$ & $\begin{array}{c}\text { Severe HIE } \\
\text { Multi organ failure }\end{array}$ & Discharged home \\
\hline 4 & 865 & 26 & Female & WD - NICU & $\begin{array}{l}\text { Treatment } \\
\text { continued }\end{array}$ & $\begin{array}{c}\text { Extreme prematurity } \\
\text { Severe pulmonary disease } \\
\text { Large bilateral HPI }\end{array}$ & Still in hospital \\
\hline 5 & 3020 & 41 & Male & WD - NICU & $\begin{array}{l}\text { Treatment } \\
\text { continued }\end{array}$ & Severe HIE & Discharged home \\
\hline 6 & 520 & 23 & Male & $\begin{array}{c}\text { WH - ANT } \\
\text { DNR - NICU }\end{array}$ & $\begin{array}{l}\text { Treatment } \\
\text { limited }\end{array}$ & $\begin{array}{l}\text { Extreme prematurity } \\
\text { Severe lung disease }\end{array}$ & $\begin{array}{l}\text { Discharged home } \\
\text { Home oxygen }\end{array}$ \\
\hline 7 & 3311 & 37 & Female & WH - ANT & $\begin{array}{l}\text { Treatment } \\
\text { continued }\end{array}$ & $\begin{array}{l}\text { Complex cardiac abnormality: hypoplastic } \\
\text { right ventricle, absent pulmonary trunk, PDA } \\
\text { not visualised, aorta-pulmonary collaterals } \\
\text { supplying lungs }\end{array}$ & Discharged home \\
\hline 8 & 2190 & 37 & Male & WH - ANT & $\begin{array}{l}\text { Treatment } \\
\text { continued }\end{array}$ & $\begin{array}{c}\text { Major congenital abnormality: Hypoplastic } \\
\text { left heart syndrome }\end{array}$ & Discharged home \\
\hline 9 & 4170 & 40 & Male & WD - NICU & $\begin{array}{l}\text { Treatment } \\
\text { continued }\end{array}$ & Severe HIE & Discharged home \\
\hline 10 & 620 & 24 & Male & DNR - NICU & $\begin{array}{l}\text { Treatment } \\
\text { limited }\end{array}$ & $\begin{array}{c}\text { Extreme prematurity } \\
\text { IVH with large unilateral HPI, }\end{array}$ & $\begin{array}{c}\text { Discharged home } \\
\text { Home oxygen }\end{array}$ \\
\hline 11 & 2470 & 34 & Male & WD - NICU & $\begin{array}{l}\text { Treatment } \\
\text { continued }\end{array}$ & Severe HIE & Discharged home \\
\hline 12 & 520 & 23 & Male & WH - ANT & $\begin{array}{l}\text { Treatment } \\
\text { limited }\end{array}$ & Extreme prematurity & $\begin{array}{c}\text { Discharged home } \\
\text { Home oxygen }\end{array}$ \\
\hline
\end{tabular}

WH - Withholding of Life Sustaining Treatment (LST); WD - Withdrawal of LST; DNR - Do not resuscitate order

NICU - Neonatal Intensive Care Unit; ANT - Antenatal; HIE - Hypoxic Ischaemic Encephalopathy; NEC - Necrotising Enterocolitis; IVH -

Intraventricular Haemorrhage; HPI - Haemorrhagic Parenchymal Infarct; PVL - Periventricular Leukomalacia; PDA - Patent Ductus Arteriosus

*Withdrawal of LST was discussed and disagreed among health care professionals 


\section{Discussion:}

In this unique prospective multicentre study, $63 \%$ of deaths were associated with some limitation of LST. Conversations about limiting LST were usually initiated by a senior member of the neonatal team, and following the initial meeting a second opinion was sought in half. Following the initial conversation between doctors and parents, half of parents made the decision to continue treatment, however over subsequent conversations a further $30 \%$ made the decision to limit treatment. Following conversations about withdrawal of LST, one in three parents decided to continue LST, but all parents who were asked to consider a DNR order consented to do so. Among 68 babies for whom limiting LST was discussed, 10\% (5 out of 52 babies) survived following a decision to limit LST, and $44 \%$ (7 out of 16) survived following decision to continue LST.

\section{Strengths of the study}

This is a prospective regional population-based study. All eligible babies born and/or admitted to neonatal units in the North East London Neonatal Network were screened over a 12 month period to June 2014, and our findings are therefore relevant to current practice. We developed systems to capture antenatal, perinatal and neonatal discussions with parents about limiting LST. Regular contact between the research team and local investigators makes us confident that ascertainment is complete. Double counting was avoided by using our national unique identifier (NHS Number), which was valuable when a baby was transferred between neonatal units. Data were collected using a validated secure online REDCap database ${ }^{18}$. All outlying and 
ambiguous data were checked with investigators and further checked and corrected if necessary at analysis.

\section{Limitations of the study}

Data were collected by reviewing medical records and not always corroborated with the clinicians involved. Antenatal discussions of obstetricians and midwives with parents regarding limiting LST for births $<23$ weeks of gestation were not collected. Details of clinical status, level of support or resuscitation provided were not collected. We have not investigated the influence of parents' beliefs, their perceptions of conversations, socioeconomic class ${ }^{19}$ or educational background on decision outcome. Details of the actual conversations were not gathered ${ }^{20}$. Neither have we been able to determine the degree to which the prior beliefs and conversational strategies of the doctors ${ }^{2122}$, or the clinical practice in each neonatal service ${ }^{23}$ may influence the outcome of these conversations, both of which may determine in part the outcome for the baby. We have not investigated doctors training and experience in limiting LST conversations $\mathrm{s}^{2425}$.

\section{Context of the study}

An elective decision to limit care occurs in up to $95 \%$ of neonatal deaths $s^{26-29}{ }^{30}$. In our study two thirds of deaths followed a decision to limit LST. A single centre study conducted in $1980 \mathrm{~s}$ reported that two out of four babies whose parents made the decision to continue LST survived with severe disability. ${ }^{31}$ More recently, Brecht and Wilkinson retrospectively examined the clinical notes of children who were recorded to have severe preterm brain injury or moderate 
to severe encephalopathy in two tertiary NICUs in South Australia between 2001 and $2006 .^{32}$ Of 78 babies with documented conversations about limiting LST, 22 (28\%) survived, there being an implicit or explicit decision not to limit LST. Hentschel et al prospectively investigated outcomes of 40 babies who were considered for limiting LST discussion in a level 3 neonatal unit from Germany over a 30 month period between 1998 and 2000. Three infants survived to neonatal unit discharge following a decision to limit LST and 3 following decision to continue LST. The explicit parental wish or decision was not stated in $9(23 \%)$ cases in Hentschel study ${ }^{33}$. The explicit shared decision between clinicians and parents was documented in all 68 cases considered for limitation of care in our study. Five babies survived after a decision to limit treatment was reached ( 2 DNR and 3 withholding cases). This may have been because at the time a decision was reached infants were physiologically stable and not requiring life-sustaining treatment. The long term outcome for babies who survive is unclear. However in the study by Brecht and Wilkinson 12 of 20 babies surviving following discussions about limiting LST were either moderately disabled and dependent on care, severely disabled and totally dependent on care, or died at follow up. ${ }^{32}$

Five babies survived after a decision to limit treatment was reached. This may have been because at the time a decision was reached infants were physiologically stable and not requiring life-sustaining treatment. 
Verhagen and colleagues reported the outcome of the 150 deaths following an end-of-life decision by a retrospective notes review, $56 \%$ were around infants who were unstable and said to have no chance of survival and $44 \%$ were stable babies with poor prognosis. ${ }^{34}$ In a similar study, Weiner et al noticed that $52 \%$ of infants died following limitation of LST were unstable, ${ }^{35}$ which is comparable to the present study. In half of our cases a second opinion was sought, in keeping with principles of good ethical decision making and clinical practice ${ }^{10}$. In $52 \%$ of cases, the recorded reasons for a decision to continue treatment were that parents had not accepted the diagnosis or prognosis. Within our society, we consider parents to be the most appropriate advocates for their babies, ${ }^{36}$ and able to make the decision to limit treatment on providing full and honest information, concrete evidence of poor prognosis and time to accept evidence ${ }^{37}$. Although there is frequently a perception that medical staff should shoulder some or all of the responsibility for such decisions ${ }^{10} 38$, parents did wish to be active in the process of making such decisions ${ }^{37}$. The most common reported reasons for limiting LST are complications of prematurity, ${ }^{1630}$ but in one recent retrospective study from a referral level IV neonatal unit, the most common given reason was major congenital anomaly, ${ }^{35}$ hence base populations may differ between studies. In our study the contributing conditions comprised congenital anomaly, hypoxic ischaemic encephalopathy and prematurity in similar proportions, and included antenatal and delivery room discussions across a whole population, rather than the restricted nature of neonatal unit admissions.

The decision to limit LST as reported by the health care team was made jointly between professionals and parents in this study as recommended by national guidelines ${ }^{910}$. Parents and 
doctors bring their own personal prior beliefs, including their cultural and spiritual backgrounds to such conversations ${ }^{22} 39$. Parents' ethnicity ${ }^{40}$ and religion ${ }^{3041}$ are reported to influence their decision on limiting LST, and different societies vary in their acceptance of explicit decisions to limit LST. Parents were present in all discussions of limiting LST in the present study, although their degree of engagement with the clinical team was not studied. There was no association between maternal ethnicity, religion and previous children, and final decision to limit LST or not in the population of varied background in the present study.

\section{Summary}

Following discussions about limiting LST, a significant proportion of parents choose to continue treatment to their babies; a proportion of these babies may survive, and a small but significant proportion of babies do survive following the decision to limit LST. It is crucial that clinicians discuss these possibilities with parents during discussions about limiting LST to ensure that parents are aware of all potential outcomes for their baby. It is also useful to document the long term outcomes of surviving babies to provide information on the likely outcomes of a decision not to limit neonatal LST. Studies of the actual decision making process between parents and the health care team around limiting LST and palliative care provision are necessary to determine any factors influencing the conversation and subsequent outcomes.

Acknowledgements: We acknowledge gratefully the contribution of the participating hospital clinical team, parents and babies whose clinical data was used. Authors would like to thank Dr Sumana Kundagrami for supporting with data collection. The study was sponsored by University College London. The National Institute for Health Research (NIHR) funded the study (RP-DG-0611-10006). Neil Marlow receives part funding from the Department of Health's NIHR Biomedical Research Centre's funding scheme at UCLH/UCL. 
Conflict of Interest: All authors have completed the Unified Competing Interest form at www.icmje.org/coi_disclosure.pdf (available on request from the corresponding author) and declare no financial relationships with any organisations that might have an interest in the submitted work in the previous 3 years. 


\section{References:}

1. Kays DW, Islam S, Richards DS, et al. Extracorporeal life support in patients with congenital diaphragmatic hernia: how long should we treat? J Am Coll Surg 2014;218(4):808-17.

2. Costeloe KL, Hennessy EM, Haider S, et al. Short term outcomes after extreme preterm birth in England: comparison of two birth cohorts in 1995 and 2006 (the EPICure studies). BMJ 2012;345:e7976.

3. Pike $\mathrm{K}$, Brocklehurst $\mathrm{P}$, Jones $\mathrm{D}$, et al. Outcomes at 7 years for babies who developed neonatal necrotising enterocolitis: the ORACLE Children Study. Arch Dis Child Fetal Neonatal Ed 2012;97(5):F318-22.

4. Moore T, Hennessy EM, Myles J, et al. Neurological and developmental outcome in extremely preterm children born in England in 1995 and 2006: the EPICure studies. BMJ 2012;345:e7961.

5. Johnson S, Wolke D, Hennessy E, et al. Educational outcomes in extremely preterm children: neuropsychological correlates and predictors of attainment. Dev Neuropsychol 2011;36(1):7495.

6. Silverman WA. Compassion or opportunism? Pediatrics 2004;113(2):402-3.

7. Hill J. When the doctor says no. Lancet 2003;361(9351):92.

8. Van Hoven MB. Compassion or opportunism? Pediatrics 2004;114(3):896-7.

9. GMC. Treatment and care towards the end of life: good practice in decision making. 2010. http://www.gmc-uk.org/End of life.pdf 32486688.pdf.

10. Larcher V, Craig F, Bhogal K, et al. Making decisions to limit treatment in life-limiting and lifethreatening conditions in children: a framework for practice. Arch Dis Child 2015;100 Suppl 2:s323.

11. Members of the Working Party. Critical care decisions in fetal and neonatal medicine: ethical issues. 2006. http://nuffieldbioethics.org/wp-content/uploads/2014/07/CCD-web-version-22-June-07updated.pdf.

12. American Academy of Pediatrics Committee on Bioethics: Guidelines on foregoing life-sustaining medical treatment. Pediatrics 1994;93(3):532-6.

13. McHaffie HE, Cuttini M, Brolz-Voit G, et al. Withholding/withdrawing treatment from neonates: legislation and official guidelines across Europe. J Med Ethics 1999;25(6):440-6.

14. Weiner J, Sharma J, Lantos J, et al. How infants die in the neonatal intensive care unit: trends from 1999 through 2008. Arch Pediatr Adolesc Med 2011;165(7):630-4.

15. Duff RS, Campbell AG. Moral and ethical dilemmas in the special-care nursery. N Engl J Med 1973;289(17):890-4.

16. Aladangady N, de Rooy L. Withholding or withdrawal of life sustaining treatment for newborn infants. Early Hum Dev 2012;88(2):65-9.

17. RCPCH. Witholding or Withdrawing Life Sustaining Treatment in Children: A Framework for Practice. Second ed: RCPCH, 2004.

18. Harris PA, Taylor R, Thielke R, et al. Research electronic data capture (REDCap)--a metadata-driven methodology and workflow process for providing translational research informatics support. J Biomed Inform 2009;42(2):377-81.

19. Banerjee J, Kaur C, Ramaiah S, et al. Factors influencing the uptake of neonatal bereavement support services - Findings from two tertiary neonatal centres in the UK. BMC Palliat Care 2016;15(1):54.

20. Shaw C, Stokoe E, Gallagher K, et al. Parental involvement in neonatal critical care decision-making. Sociol Health IIIn 2016; ISSN 0141-9889, pp. 1-26, doi: 10.1111/1467-9566.12455.

21. De Leeuw R, Cuttini $M$, Nadai $M$, et al. Treatment choices for extremely preterm infants: an international perspective. J Pediatr 2000;137(5):608-16. 
22. Gallagher K, Aladangady N, Marlow N. The attitudes of neonatologists towards extremely preterm infants: a Q methodological study. Arch Dis Child Fetal Neonatal Ed 2015.

23. Orfali K. Parental role in medical decision-making: fact or fiction? A comparative study of ethical dilemmas in French and American neonatal intensive care units. Soc Sci Med 2004;58(10):200922.

24. Boss RD, Hutton N, Donohue PK, et al. Neonatologist training to guide family decision making for critically ill infants. Arch Pediatr Adolesc Med 2009;163(9):783-8.

25. Gallagher K, Shaw C, Marlow N. Experience of training in communication skills among trainee neonatologists. Arch Dis Child Fetal Neonatal Ed 2015;100(5):F468.

26. Verhagen AA, Dorscheidt JH, Engels B, et al. End-of-life decisions in Dutch neonatal intensive care units. Arch Pediatr Adolesc Med 2009;163(10):895-901.

27. Ryan CA, Byrne $P$, Kuhn $S$, et al. No resuscitation and withdrawal of therapy in a neonatal and a pediatric intensive care unit in Canada. J Pediatr 1993;123(4):534-8.

28. Singh J, Lantos J, Meadow W. End-of-life after birth: death and dying in a neonatal intensive care unit. Pediatrics 2004;114(6):1620-6.

29. Wall SN, Partridge JC. Death in the intensive care nursery: physician practice of withdrawing and withholding life support. Pediatrics 1997;99(1):64-70.

30. Roy R, Aladangady N, Costeloe $\mathrm{K}$, et al. Decision making and modes of death in a tertiary neonatal unit. Arch Dis Child Fetal Neonatal Ed 2004;89(6):F527-30.

31. Whitelaw A. Death as an option in neonatal intensive care. Lancet 1986;2(8502):328-31.

32. Brecht $M$, Wilkinson DJ. The outcome of treatment limitation discussions in newborns with brain injury. Arch Dis Child Fetal Neonatal Ed 2015;100(2):F155-60.

33. Hentschel $R$, Lindner $K$, Krueger $M$, et al. Restriction of ongoing intensive care in neonates: a prospective study. Pediatrics 2006;118(2):563-9.

34. Verhagen AA, de Vos M, Dorscheidt JH, et al. Conflicts about end-of-life decisions in NICUs in the Netherlands. Pediatrics 2009;124(1):e112-9.

35. Weiner J, Sharma J, Lantos J, et al. Does diagnosis influence end-of-life decisions in the neonatal intensive care unit? J Perinatol 2015;35(2):151-4.

36. Saigal S, Stoskopf BL, Feeny D, et al. Differences in preferences for neonatal outcomes among health care professionals, parents, and adolescents. JAMA 1999;281(21):1991-7.

37. McHaffie HE, Lyon AJ, Hume R. Deciding on treatment limitation for neonates: the parents' perspective. Eur J Pediatr 2001;160(6):339-44.

38. Brinchmann BS, Forde R, Nortvedt P. What matters to the parents? A qualitative study of parents' experiences with life-and-death decisions concerning their premature infants. Nurs Ethics 2002;9(4):388-404.

39. Cuttini M, Nadai M, Kaminski M, et al. End-of-life decisions in neonatal intensive care: physicians' self-reported practices in seven European countries. EURONIC Study Group. Lancet 2000;355(9221):2112-8.

40. Moseley KL, Church A, Hempel B, et al. End-of-life choices for African-American and white infants in a neonatal intensive-care unit: a pilot study. J Natl Med Assoc 2004;96(7):933-7.

41. da Costa DE, Ghazal H, Al Khusaiby S. Do Not Resuscitate orders and ethical decisions in a neonatal intensive care unit in a Muslim community. Arch Dis Child Fetal Neonatal Ed 2002;86(2):F115-9. 
Figure 1: Gestational age distribution of infants studied $(n=87)$

Figure 2: Limiting LST conversation and outcomes $(n=87)$

WD - Withdrawal of LST, WH - Withholding of LST and DNR - Do not Resuscitate Order 